\title{
A new species of viviparous moth fly (Diptera, Psychodidae, Psychodinae) from the Brazilian Amazon
}

\author{
Danilo Cordeiro ${ }^{1} \&$ Freddy Bravo $^{2,3}$
}

\author{
${ }^{1}$ Programa de Pós-graduação em Entomologia, Departamento de Zoologia, \\ Universidade Federal do Paraná - UFPR \\ CP 19020, CEP 81531-980, Curitiba, PR, Brazil \\ ${ }^{2}$ Departamento de Ciências Biológicas, \\ Universidade Estadual de Feira de Santana-UEFS, \\ Av. Universitária s/n, CEP 44031-460, Feira de Santana, BA, Brazil \\ ${ }^{3}$ Corresponding author: Freddy Bravo,e-mail: freddy11bravo@yahoo.com.br
}

CORDEIRO, D. \& BRAVO, F. 2008. A new species of viviparous moth fly (Diptera, Psychodidae, Psychodinae) from the Brazilian Amazon. Biota Neotrop. 8(2): http://www.biotaneotropica.org.br/v8n2/en/ abstract?article+bn02208022008.

Abstract: A new species of Psychoda Latreille from Brazil is described and illustrated, and represents the first record of viviparous species in the genus Psychoda.

Keywords: Diptera, Psychodidae, Psychoda, new species, Amazonian, Brazil.

CORDEIRO, D. \& BRAVO, F. 2008. Espécie nova de psicodídeo vivíparo (Diptera, Psychodidae, Psychodinae) da Amazônia brasileira. Biota Neotrop. 8(2): http://www.biotaneotropica.org.br/v8n2/pt/ abstract?article+bn02208022008

Resumo: Uma nova espécie de Psychoda Latreille do Brasil é descrita. Este trabalho apresenta o primeiro registro de uma espécie vivípara no gênero Psychoda.

Palavras-chave: Diptera, Psychodidae, Psychoda, espécie nova, Amazônia, Brasil. 


\section{Introduction}

The genus Psychoda Latreille, a globally distributed genus, is represented by fifty-five recent species from the Neotropics, five of which are known from Brazil (Bravo et al. 2006): P. divaricata Duckhouse from the state of Santa Catarina, P. dantilandensis Bravo, Cordeiro \& Chagas and $P$. serraorobonensis Bravo, Cordeiro \& Chagas, both from the state of Bahia, P. alternata Say, a cosmopolitan species recorded from the state of Bahia, and P. zetoscota Quate, known from Panama, Trinidad and the state of Bahia, Brazil.

Viviparity, a form of reproduction in which the larvae hatch inside the female before deposition, is a widely distributed phenomenon in Diptera and has been recorded in 22 families (Meier et al. 1999). Viviparity is presently known for only one species of the family Psychodidae - Philosepedon humeralis Meigen (Laurence 1997) where thirty-three larvae were discovered in the genital ducts of a female of this species (Meier et al. 1999).

In this paper we describe a new species of Psychoda from the Brazilian Amazon, and also report viviparity for the first time in this genus.

\section{Materials and Methods}

All specimens examined were treated with $10 \% \mathrm{KOH}$, dehidrated and mounted in Canada balsam. Morphological terminology follows that of McAlpine (1981). The specific morphological terminology for Psychodidae follows that of Duckhouse (1990) and Bravo (2006). The wide diagnosis of Bravo et al. (2006) was accepted as the definition of the genus Psychoda. The specimens were deposited in the Coleção Entomológica do Museu de Zoologia da Universidade Estadual de Feira de Santana, Feira de Santana, Bahia, Brazil (MZUEFS) and Coleção de Invertebrados do Instituto Nacional de Pesquisas da Amazônia (INPA).

\section{Results}

1. Psychoda amazonensis Cordeiro \& Bravo, sp. nov. (Figures 1-14)

Type material: Holotype male, BRAZIL, Amazonas, Silvis, Saracá, 30.VI.1997, without name of collector (INPA); 1 paratype male, same locality and date as holotype, without name of collector (INPA); 1 paratype male, same locality and date as holotype, without name of collector (MZUEFS); 5 paratype female, same locality and date as holotype, without name of collector (INPA); 3 paratype female, same locality and date as holotype, without name of collector (MZUEFS)

Diagnosis: This species can be recognized by the following combination of characters: eye bridge with 4 facet rows, separated by 0.3 facet diameters; ascoids 4-branched, 3 superior and 1 inferior; labellum with 4 teeth; gonostylus with a long setae near the base; gonocoxal bridge posteriorly expanded, longer than the aedeagus; subgenital plate of female reduced, subquadrate, with small apical lobes; genital digit absent.

Male: Eye bridge with 4 facet rows, separated by 0.3 facet diameters (Figure 1). Interocular suture (Figure 1). Four postocular alveoli; hair patch of vertex undivided; hair patch of frons extends to facet row 2 (Figure 1). Antenna of male similar to the female (see description of antenna in female description); ascoids lost. Labellum with 4 teeth, 3 apical and 1 smaller one near the apex, and 2 setae (Figure 5). Palpus formula = 1.0:0.9:0.9:1.1 (Figure 6). Wing (Figure 7): Sc short, not reaching the base of Rs; radial fork apical to medial fork; $\mathrm{R}_{5}$ ending at wing tip. Male terminalia: epandrium, cercus, gonocoxite, and gonostyle pilose (Figures 8, 9, 10); hypandrium naked (Figure 10); sternite 10 with apical micropilosity (Figure 9); tergite 10 with small bristles at the apex. Hypandrium band-like, as wide as the widest portion of the gonostylus (Figure 10). Gonocoxite as long as the gonostylus (Figure 8). Gonocoxal apodemes fused forming a gonocoxal bridge, with base bilobed and expanded posteriorly, longer than aedeagus, $0.6 \mathrm{X}$ the length of gonostylus, and ending in a pointed apex (Figures 8,10); base of posterior expansion of gonocoxal bridge with ventral pilosity (Figure 11); gonocoxal bridge articulated anteriorly to aedeagus (Figure 8). Gonostylus slightly curved, narrower at apex, with 2 short setae in the dorsal surface, near the apex and 1 long setae in the ventral surface, near the base (Figure 10). Epandrium subquadrate (Figure 9). Cercus piriform with 1 apical tenaculum (Figure 8). Sternite 10 wide in lateral view (Figure 8); in ventral view with lateral margins divergent and apical margin straight (Figure 9). Aedeagus simple, wide in lateral view, with rounded apex (Figure 10); paramere absent.

Female (Figure 12): Similar to male. Antenna: scape cylindrical, 1.5X the length of the pedicel (Figure 2); pedicel spherical (Figure 2); flagellum with 14 flagellomeres, 1-10 nodiform (Figures 2, 4); flagellomere 11 with spine and short neck (Figure 4); flagellomeres 12-14 subspherical, reduced and fused (Figure 4); flagellomeres 13 and 14 with spines (Figure 4); ascoids with four branches (Figure 3). Female terminalia: cercus short, 1.3X the length of the subgenital plate; subgenital plate of female (S8) reduced, subquadrate, not reaching lateral margins of the eighth tergite (T8); lobes reduced, widely separated; genital digit absent; spermatheca as shown in the figure 12 .

\section{Comments on Viviparity and the Larvae}

Eight females of Psychoda amazonensis sp. nov. were prepared and mounted in Canada balsam; only after this procedure was completed was the presence of larvae in the abdominal cavity noted. All larvae in the abdomen had their head capsules oriented towards the anterior end of the female. The number of larvae in the abdomens of the females varies from 2 to 46: 2 larvae (1 specimen), 4 (1), 15 (1), 20 (2), 22 (1), 33 (1), and 46 (1). Some characters of the larva were not visible in the preparation. The head capsule was evident and long (Figure 13). A pair of ocelli was observed on the head capsule (Figure 13). The posterior spiracle is present in a terminal, short, siphon (Figure 14).

\section{Discussion}

Psychoda amazonensis sp. nov. can be distinguished from other species of Psychoda by the absence of parameres in male terminalia, females with ascoids with 4 branches, reduced subgenital plate, and absence of a digit in the subgenital plate.

Species of the subgenus Falsologima Ježek \& Van Harten of the genus Psychoda have males with ascoids with 4 branches in the flagellomeres, while females have ascoids with 3 branches (Ježek \& Van Harten, 2005). The new species described here cannot be assigned to this subgenus because the ascoids of females have 4 branches, similar to males of Falsologima. The ascoids of P. amazonensis sp. nov. males are unknown.

Psychoda amazonensis sp. nov. is morphologically similar to Psychoda. quiniversa Quate from Costa Rica. Six characteristics are similar in the two species: 1) hair patch of frons extend to facet row $2 ; 2$ ) females with $11^{\text {th }}, 13^{\text {th }}$ and $14^{\text {th }}$ flagellomeres with spines, $12^{\text {th }}$ without spine; 3 ) ascoids of females with 4 branches; 4 ) paramere of male terminalia absent; 5) posterior expansion of gonocoxal bridge with basal ventral pilosity (small setose lobe under center of aedeagus of Quate 1996); 6) gonostylus with a long setae in the ventral surface, near the base. These morphological similarities suggest a common 

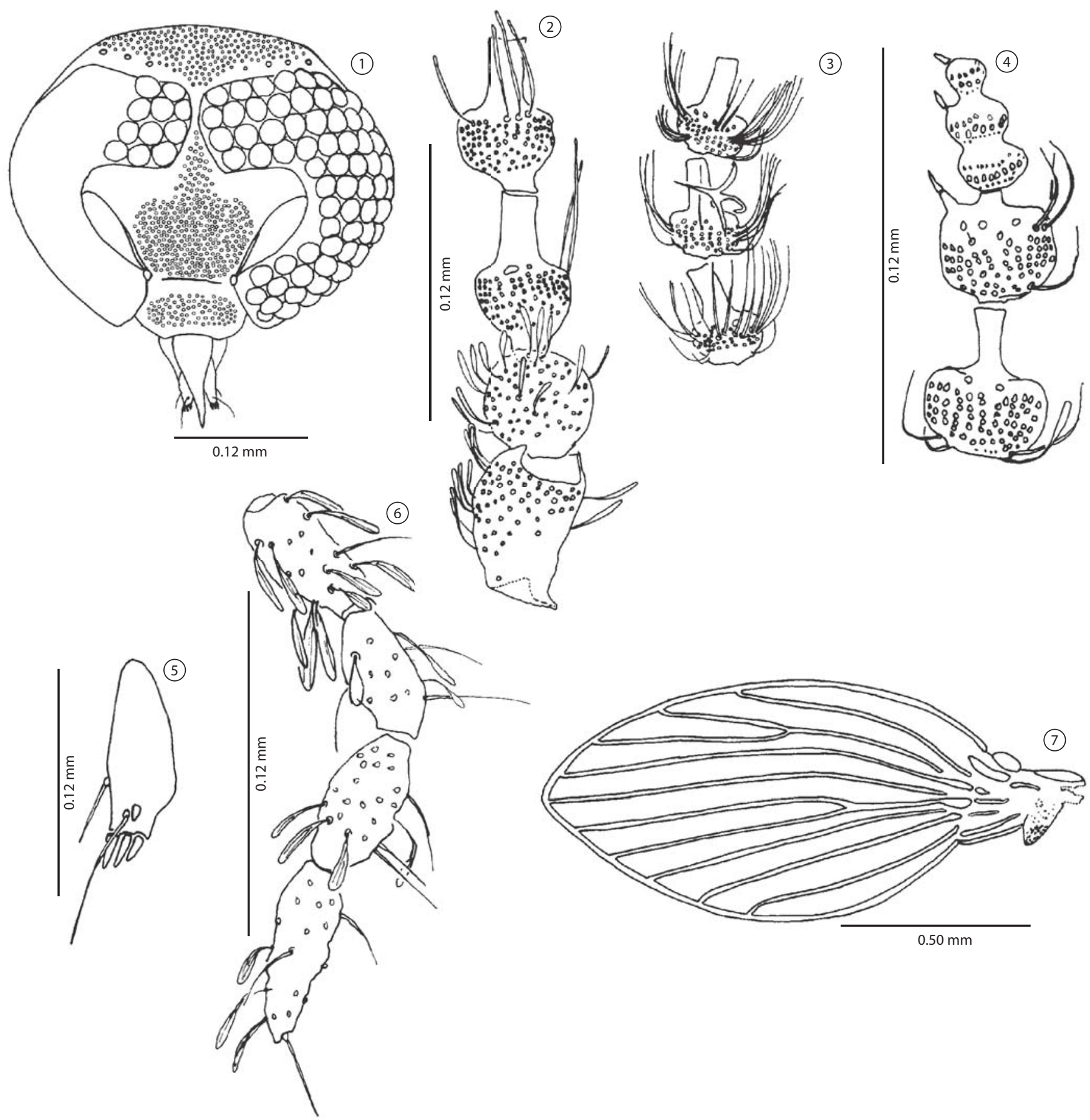

Figures 1-7. Psychoda amazonensis Cordeiro \& Bravo, sp. nov. Male 1,5-7. Female 2-4. 1. Head. 2. Antenna: scape, pedicel and basal flagellomeres. 3. Antenna, flagelomeres 3-5. 4. Antenna, flagelomeres 10-14. 5. Labellum; 6. Palpus. 7. Wing.

Figuras 1-7. Psychoda amazonensis Cordeiro \& Bravo, sp. nov. Macho 1, 5-7. Fêmea 2-4. 1. Cabeça. 2. Antena: escapo, pedicelo e flagelômeros basais. 3. Antena, flagelômeros 3-5. 4. Antena, flagelômeros 10-14. 5. Labela. 6. Palpo. 7. Asa.

ancestrality between these two species that can be tested with future phylogenetic studies.

Psychoda amazonensis sp. nov. can be distinguished from $P$. quiniversa, by three principal characters: 1) eye bridge of P. quiniversa wider than $P$. amazonensis sp. nov. (5 facet rows vs. 4 facet rows); 2) posterior expansion of the gonocoxal apodeme long in the new species and small in P. quiniversa (Figure 9, Quate 1996: Figure 25a); and 3); subgenital plate reduced in the new species and large (normal sized) in P. quiniversa

The observation of larvae in eight females of $P$. amazonensis sp. nov. represents the first record of viviparity for the genus Psychoda, and the second record for the family Psychodidae. The only other species of Psychodidae demonstrating viviparity is Philosepedon humeralis, described by Laurence (1997) from 1 female that contained 

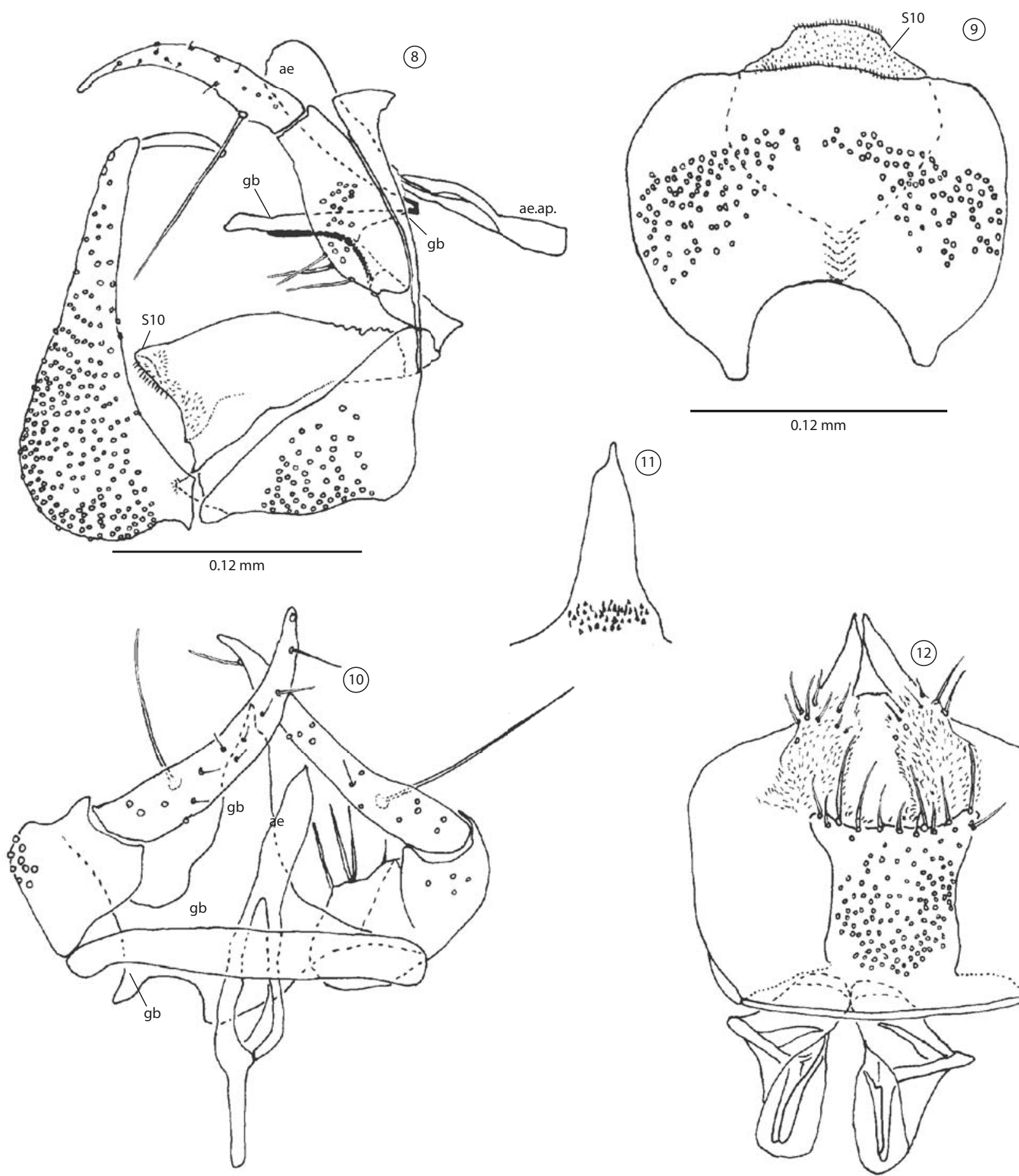

$0.12 \mathrm{~mm}$

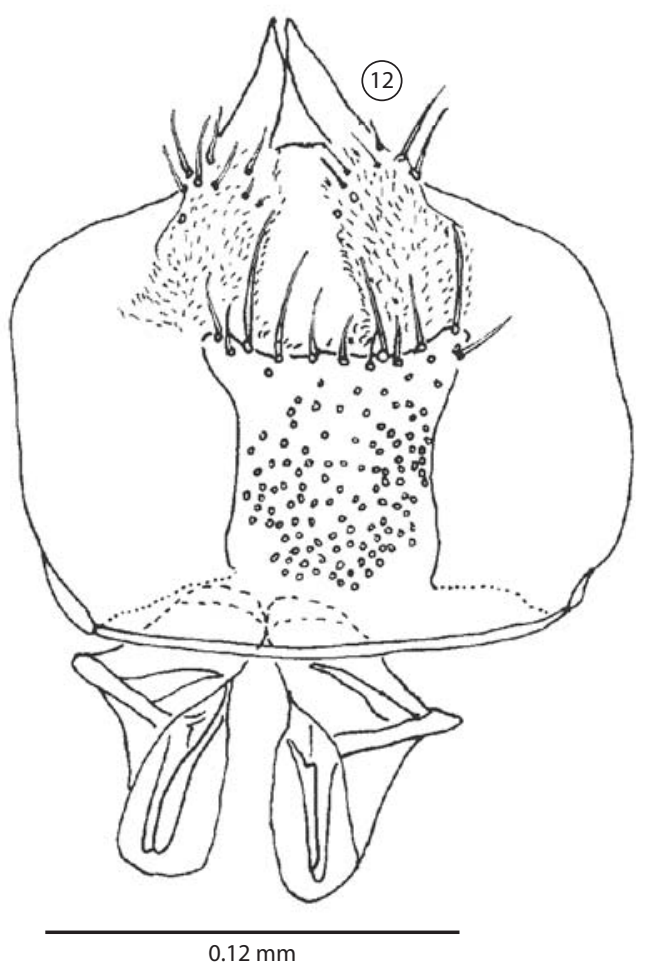

Figures 8-12. Psychoda amazonensis Cordeiro \& Bravo, sp. nov. Male, 8-11. Female, 12. 8. Male terminalia, lateral. 9. Male terminalia, ventral. 10. Male terminalia, dorsal. 11. Male terminalia, lobe of gonocoxal bridge, ventral. 12. Female terminalia. ae $=$ aedeagus; ae.ap. $=$ aedeagal apodeme; $g b=$ gonocoxal bridge; $\mathrm{S} 10=$ sternite 10 .

Figuras 8-12. Psychoda amazonensis Cordeiro \& Bravo, sp. nov. Macho, 8-11. Fêmea, 12. 8. Terminália masculina, lateral. 9. Terminália masculina, ventra. 10. Terminália masculina, dorsal. 11. Terminália masculina, complexo da ponte gonocoxal, ventral. 12. Terminália feminina. ae = edeago; ae.ap. $=$ apódema edeagal; gbc = complexo da ponte gonocoxal; S10 = esternito 10 . 

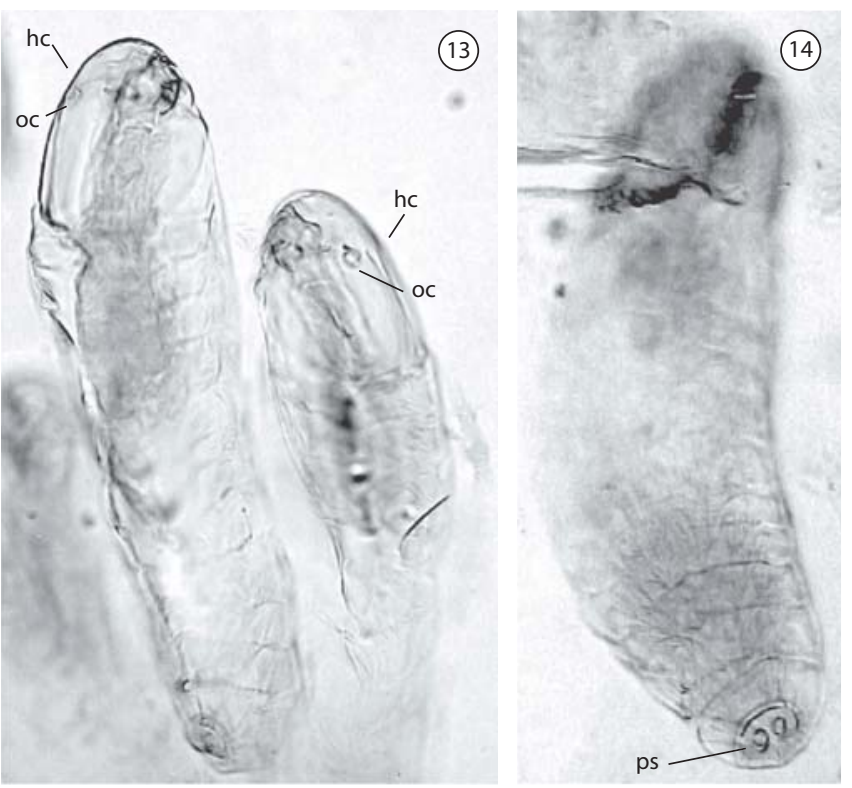

Figures 13-14. Psychoda amazonensis Cordeiro \& Bravo, sp. nov. 13. Larvae, anterior end. 14. Larvae, posterior end. hc = head capsule; oc = ocellus; os $=$ posterior spiracle.

Figuras 13-14. Psychoda amazonensis Cordeiro \& Bravo, sp. nov. 13. Larva, extremo anterior. 14. Larva, extremo posterior. hc = cápsula cefálica; oc = celo; os = espiráculo posterior.

approximately 37 larvae. The position of the larvae in the abdomen of the new species is identical to that observed in Ph. humeralis, with the head capsule oriented towards the anterior end of the female. According to Laurence (1997), the general position of the larvae of Ph. humeralis in the abdomen of the female is the same as that expected for the eggs in a normal gravid fly, and suggests that the eggs were fertilized in situ in the ovary.

The number of larvae in the females of $P$. amazonensis sp. nov. varied from 2 to 46 , and thus classified it as a multilarviparous species. According to Meier et al. (1999), shortened female terminalia (as observed in P. amazonensis sp. nov.) represents one of the morphological adaptations of species of Diptera to viviparity. This characteristic suggests that this is, in fact, an obligatorily viviparous species.

\section{Acknowledgments}

This work was developed as a finish work of undergraduate course of Biology at Universidade Estadual de Feira de Santana, BA. DC received a PROBIC/UEFS grant. FB received financial support from CNPq (470754/2003-6) and FAPESB (PPP) and has a research grant from CNPq (306426/2006-4).

\section{References}

BRAVO, F. 2006. The taxonomy of Neotropical Brunettiina (Diptera, Psychodidae, Psychodinae, Mormiini) with descriptions of ten new species from Brazil and comments on the generic classification of this subtribe. Zootaxa. (1134): 1-28.

BRAVO, F., CORDEIRO, D. \& CHAGAS, C. 2006. Two new species and new records of Psychoda Latreille (Diptera, Psychodidae, Psychodinae) from Brazil, with comments on supraspecific classification of the genus. Zootaxa. (1298): 1-15.

DUCKHOUSE, D.A. 1990. The Australasian genera of Pericomoid Psychodidae (Diptera) and the status of related Enderlein genera in the Neotropics. Invertebr. Taxon. 3(6): 721-746.

JEŽEK, J. \& VAN HARTEN, A. 2005. Further new taxa and little-known species of non-biting moth flies (Diptera, Psychodidae) from Yemen. Acta Entomol. Mus. Nat. Pragae. 45: 199-220. LAURENCE, B.R. 1997. Larval development within the abdomen of female Philosepedon humeralis $\mathrm{Mg}$. (Dipt. Psychodidae). Entomol. Monthly Mag. 133: 256.

McALPINE, J.F. 1981. Morphology and terminology: adults. In Manual of Neartic Diptera (J.F. Mcalpine, B.V. Peterson, G.E. Shewell, H.J. Teskey, J.R. Vockeroth \& D.M. Wood, eds.). Research Branch, Agriculture Canada, Ottawa. v. 1, Monograph n ${ }^{\circ} 27$, p. 9-63.

MEIER, R., KOTBRA, M. \& FERRAR, P. 1999. Ovoviviparity and viviparity in the Diptera. Biol. Rev. 74(3): 199-258.

QUATE, L.W. 1996. Preliminary taxonomy of Costa Rican Psychodidae (Diptera), exclusive of Phlebotominae. Rev. Biol. Trop. 44: 1-81 (Supplement 1).

Data Received 14/11/07 Revised 20/05/08 Accepted 11/06/08 